\section{Praedicere Possumus: An Italian web-based application for predictive microbiology to ensure food safety}

\section{Pierluigi Polese, ${ }^{1}$ Manuela Del Torre, ${ }^{2}$ \\ Mara Lucia Stecchini ${ }^{2}$ \\ ${ }^{1}$ Polytechnic Department of Engineering and Architecture, ${ }^{2}$ Department of Agricultural, Food, Environmental and Animal Sciences, University of Udine, Italy}

\begin{abstract}
The use of predictive modelling tools, which mainly describe the response of microorganisms to a particular set of environmental conditions, may contribute to a better understanding of microbial behaviour in foods. In this paper, a tertiary model, in the form of a readily available and userfriendly web-based application Praedicere Possumus (PP) is presented with research examples from our laboratories. Through the PP application, users have access to different modules, which apply a set of published models considered reliable for determining the compliance of a food product with EU safety criteria and for optimising processing throughout the identification of critical control points. The application pivots around a growth/no-growth boundary model, coupled with a growth model, and includes thermal and non-thermal inactivation models. Integrated functionalities, such as the fractional contribution of each inhibitory factor to growth probability (f) and the time evolution of the growth probability $\left(\mathrm{P}_{\mathrm{t}}\right)$, have also been included. The PP application is expected to assist food industry and food safety authorities in their common commitment towards the improvement of food safety.
\end{abstract}

\section{Introduction}

A model can be conceptualized as a simplified representation of reality and then defined as a set of assumptions that will result in mathematical equations, which can be programmed in a computer tool (Zwietering and den Besten, 2011). Mathematical models, which are useful and usable for estimating the microbial responses in foods, can be embedded and used in predictive microbiology (Baranyi and Roberts, 1995). The basic idea underlying predictive microbiology is that the behaviour of microorganisms is deterministic and able to be predicted from knowledge of the microorganism itself, and the immediate environment of the microorganisms (McMeekin et al., 2010). In the last two decades, predictive microbiology has established itself as a sub-discipline of food microbiology and of technology that are required for its applications (McMeekin et al., 2008). This sub-discipline has been recently accepted as a tool for assessing and managing food safety, which is essentially based on the control of hazard.

Modelling tools and data resulting from predictive microbiology can deliver benefits to both the food industry and food inspectors. In an industrial context, use of these tools could help producers in designing safe processes and in determining storage conditions. For official controls, modelling could be valuable for deciding how to carry out risk-based controls and for their prioritisation

For effective applications of predictive modelling into real world food, modelling tools should be intended for practical use, enabling users to retrieve information intuitively and providing an easy way to access prediction (Polese et al., 2016). To facilitate this process, an accessible and affordable modelling tool (Praedicere Possumus, PP) to meet the demand of producers and safety authorities has been proposed.

\section{Praedicere Possumus: the models and the structure}

The web-based application PP, which is available on the web site of the University of Udine (Italy) at http://praedicere .uniud.it/, provides a deterministic approach for prediction. The application contains a group of models that address the growth probability, the growth kinetics, and the thermal and non-thermal inactivation kinetics of ten foodborne pathogenic bacteria. The core of PP includes both a growth/nogrowth $(\mathrm{G} / \mathrm{NG})$ model and a growth/inactivation partitioning parameter $(\mathrm{P})$, termed growth probability, which quantifies the distance between the growth boundary and the specific product characteristics (Polese et al., 2011). When $\mathrm{P}$ calculated from the G/NG model is $>0.1$, growth is likely (Tienungoon et al., 2000) and the pathogen population density is estimated with a kinetic approach, which uses a three-phase linear model (TPL) (Buchanan et al., 1997). A Gamma type model (Zwietering et al., 1992), which was inspired from the structure of the equation described by Mejlholm
Correspondence: Mara Lucia Stecchini, Department of Agricultural, Food, Environmental and Animal Sciences, University of Udine, via Sondrio 2/a, Udine, Italy.

Tel.:+39.0432.558132 - Fax: +39.0432.558130.

E-mail: mara.stecchini@uniud.it

Key words: Predictive microbiology, Modelling, Food safety, Praedicere Possumus, Web application.

Acknowledgments: PP was developed within the MIUR Project "Proof of Concept Network" (PoCN), managed by AREA Science Park (Trieste, Italy). The dynamic Excel version of the application is available on request to the authors.

Contributions: the authors contributed equally

Conflict of interest: the authors declare no potential conflict of interest.

Funding: none.

Received for publication: 21 July 2017.

Revision received: 10 October 2017.

Accepted for publication: 10 October 2017.

This work is licensed under a Creative Commons Attribution-NonCommercial 4.0 International License (CC BY-NC 4.0).

(C) Copyright P. Polese et al., 2018

Licensee PAGEPress, Italy

Italian Journal of Food Safety 2018; 7:6943

doi:10.4081/ijfs.2018.6943

and Dalgaard (2009), is used as secondary model for the estimation of the parameter $\mu_{\max }$ over discrete time intervals. To take into account the lag time, the relative lag time (RLT), which represents the ratio of the lag time and the generation time (Mellefont and Ross, 2003) was included in the PP. For the prediction of population changes during processing/storage, which is estimated in relation to the specific conditions monitored at each processing/ $\mathrm{period} / \mathrm{step}$, the cumulative approach for the lag time applicable to microbial growth under dynamic conditions (Koutsoumanis, 2001) was incorporated.

In environmental conditions precluding growth ( $\mathrm{P} \leq 0.1)$, non-thermal inactivation over time is likely (McQuestin et al, 2009), and the pathogen population density is determined by the Weibull equation (Mafart et al., 2002), with the time of first decimal reduction estimated with the model of Zhang et al. (2010).

To optimise the use of industrial data, the application offers two functionalities, namely the fractional contribution of each inhibitory factor to growth probability (f) 
and the time-dependent probability parameter $\left(\mathrm{P}_{\mathrm{t}}\right)$ (Polese et al., 2014, 2017). Applying a Gamma structure (Zwietering et al., 1992), the fractional contribution of each inhibitory factor to growth probability was evaluated as a function of the difference between the actual level of the factor and the inhibiting value, adjusted for the suboptimal interval of the factor. This parameter provides a quantitative estimation of the impact of each factor on the growth probability of the pathogen. The time-dependent growth probability parameter was described as a function of the growth probability and the growth rate (GR) and represents the change in growth probability over time.

To assist the user in organizing information around their own specific needs, the menu structure is organised through modules. The generic module provides the opportunity to run many different food safety scenarios, i.e. to predict what may happen to all the 10 pathogenic bacteria in terms of growth probability ( $\mathrm{P}$ and $\mathrm{P}_{\mathrm{t}}$ ), growth and thermal/non thermal inactivation under different process/storage temperatures or over different storage times. Prediction can be provided based on key factors, such as $\mathrm{pH}$ and $\mathrm{a}_{\mathrm{w}}$, as well as a function of a generic gamma factor $(\mathrm{g})$ for other possible controlling factors. This module can help users in screening the various hazards likely to be involved in the selected conditions, which can include processing and/or storage situations.

The application of the specific module is the assessment of each pathogen probability of growth, growth or inactivation in response to the key controlling factors and other additional environmental parameters, such as organic acids and food additives. The (f) option, which reflects the size of each applied hurdle, can assist food developers in designing products under conditions that are closer to microbial growth/nogrowth boundaries (Pujol et al., 2012). The introduction of the variable outcome $\left(\mathrm{P}_{\mathrm{t}}\right)$, which takes into account the storage time in a time-dependent probability parameter, provides a mechanism for the simulation of the growth probability of a pathogen related to a specific time. This option is intended to be used in the estimation/validation of the shelf life of food based on the potential growth of the pathogen of concern.

A process module has been developed to predict a pathogen behaviour as a function of processing/storage conditions, including different steps, which are modelled such as growth probability, timedependent probability, growth and inactivation. This modelling approach helps users to optimise processes and to define critical control points and critical limits, as well as to determine safe corrective actions when processing deviations occur. Research examples are given on the practical use of PP for the growth prediction of Listeria monocytogenes in meat products.

\section{How to determine the compli- ance of a ready-to-eat food with the European Commission Regulation 2073/2005 criteria for $L$. monocytogenes taking into consideration the effect of pro- cessing?}

Pitina is a low-acid non-fermented meat product made by small producers who follow a traditional local recipe from the north east of Italy. This artisanal product is a ready-to-eat (RTE) food that is actually consumed raw after being processed for about 30 days. Applying the PP specific module to estimating growth probability, Pitina, at the end of processing, was found to be unable to support the growth of $L$. monocytogenes at refrigeration temperature $\left(4^{\circ} \mathrm{C}\right)$, at the most likely storage temperature $\left(6^{\circ} \mathrm{C}\right)$ and at abused temperature $\left(12^{\circ} \mathrm{C}\right)$, with $\mathrm{pH}$ and $\mathrm{a}_{\mathrm{w}}$ being the substantial factors contributing to stability (Figures 1 and 2). A challenge test ended up with the same conclusion, with the inoculation find- ings lacking of flexibility since results are only valid under the challenge test conditions (Beaufort, 2011).

However, even if Pitina belongs to the category of products that are unable to support the growth of L. monocytogenes, this does not mean that the population of the pathogen in Pitina during storage in the market would not exceed its maximum allowable concentration. The non-compliance to the safety criterion will be dependent on the evolution of the initial contamination during processing. Therefore, the question was whether the process conditions could be favourable or unfavourable for growth of L. monocytogenes (Polese et al., 2014). Applying the PP process module, each processing stage was separately tested, each growth probability was calculated and the pathogen concentration at the end of each stage estimated (Table 1). Only one of the two drying stages had an influence on the probability of growth $(\mathrm{P}=0.25)$ and on the population size, which was predicted to increase by $0.16 \log \mathrm{CFU} \mathrm{g}^{-1}$. The inoculation study, showing a small increase in the pathogen numbers, confirmed the validity of the prediction. Null growth probability was predicted and no-growth was observed in the latter stages of the process and during storage in MAP.

Thus, PP proved to be a valuable tool for producers and safety authorities for determining the compliance of an RTE product, such as Pitina, with the EC safety criteria (EC 2005, 2007), as well as to identify critical stages of the process.

\section{Are specific processing conditions for artisanal salami favourable or unfavourable for L. monocytogenes growth?}

In the north east of Italy, artisanal salami are manufactured mainly during cold seasons, from fresh pork meat, pork fat and

Table 1. Comparison of observed and predicted responses of L. monocytogenes in Pitina samples during processing and storage.

\begin{tabular}{lccccc}
$\begin{array}{l}\text { Pitina processing } \\
\text { steps }\end{array}$ & $\begin{array}{c}\text { Observed L. monocytogenes } \\
\text { growth response }\end{array}$ & & $\begin{array}{c}\text { Predicted L. monocytogenes growth } \\
\text { response } \\
\text { Observed positive }\end{array}$ \\
Drying (I) & 0 & $0.16(0.03)^{\mathrm{e}}$ & 0.25 & 0.04 & 0.16 \\
Smoking (I) & 0 & - & 0.00 & 0.04 & - \\
\hline Smoking (II) & 0 & - & 0.00 & 0.04 & - \\
Ripening & 0 & - & 0.00 & 0.04 & - \\
\hline Shelf life & 0 & - & 0.00 & 0.04 & - \\
\hline
\end{tabular}

aPercentage (\%) of Listeria positive samples (log increase $>0.5 \mathrm{Log} \mathrm{CFU} \mathrm{g}^{-1}$ ); ${ }^{b} \log \mathrm{CFU} \mathrm{g}^{-1}$ increase was calculated as the difference between the log concentration (mean value) reached in each stage and the initia

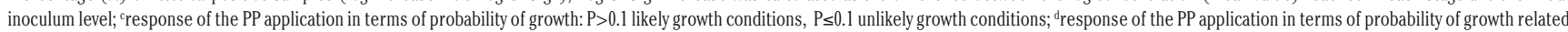
to a specific time: $\mathrm{P}_{\mathrm{t}}>0.1$ likely growth conditions, $\mathrm{P}_{\mathrm{t}} \leq 0.1$ unlikely growth conditions; ${ }^{\mathrm{e}}$ standard error. 
salt by means of techniques derived from local traditions. To preserve variability, starter cultures are not used and the fermentation process relies on indigenous microflora whose origins result from the raw material, mainly meat, or from the environment. When the dependence of the probability of growth, and of the growth of L. monocytogenes on temperature, $\mathrm{pH}, \mathrm{a}_{\mathrm{w}}$, lactic acid and indigenous lactic acid bacteria of salami was predicted by the PP process module (in its Excel dynamic version), it appeared that the contribution of the inhibitory factors in the artisanal processing did not result in an early inhibition of Listeria growth (Figures 3 and 4) (Polese et al., 2017). The predicted final magnitude level of Listeria population was $\geq 2 \log$ in 2 out of the 5 salami batches examined, exceeding the tolerated level of $2.0 \log \mathrm{CFU}$ $\mathrm{g}^{-1}$ adopted by the EC Regulation. Applying PP in its dynamic (Bernaerts et al., 2004) version (using a numerical approach for solving differential equation models) to potential scenarios that included the contribution of starter cultures, the onset of Listeria inhibition was predicted earlier,

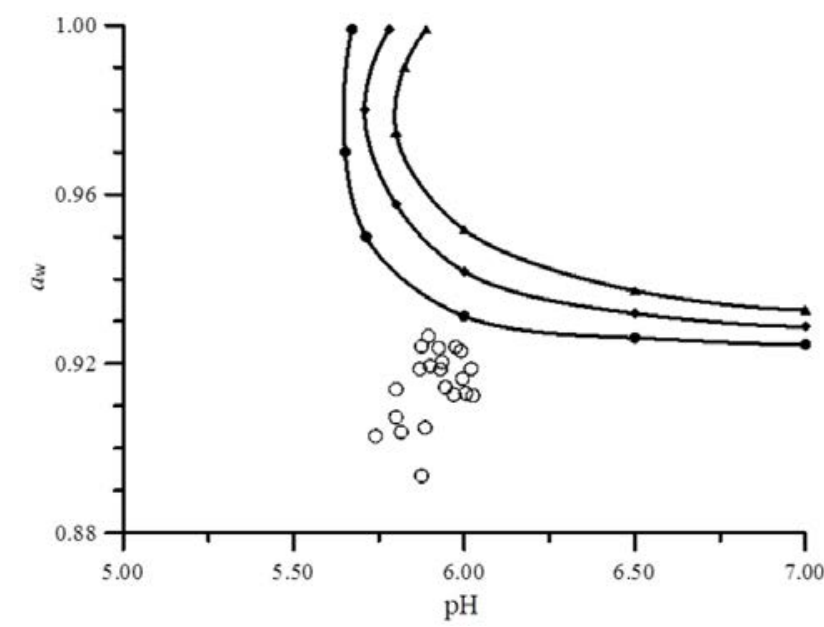

Figure 1. Growth/no growth boundaries at $\mathrm{P}=0.1$ for $L$. monocytogenes in Pitina at $4^{\circ} \mathrm{C}(\Delta), 6^{\circ} \mathrm{C}(\bullet)$ and $12^{\circ} \mathrm{C}(\bullet)$ with respect to $\mathrm{pH}$ and $\mathrm{a}_{\mathrm{w}}$. Products to the left of growth boundary do not support the growth of the pathogen at the specified temperature. Dot distances to the G/NG boundary reflect variability in stability of the 21 samples assessed through PP.

(a)

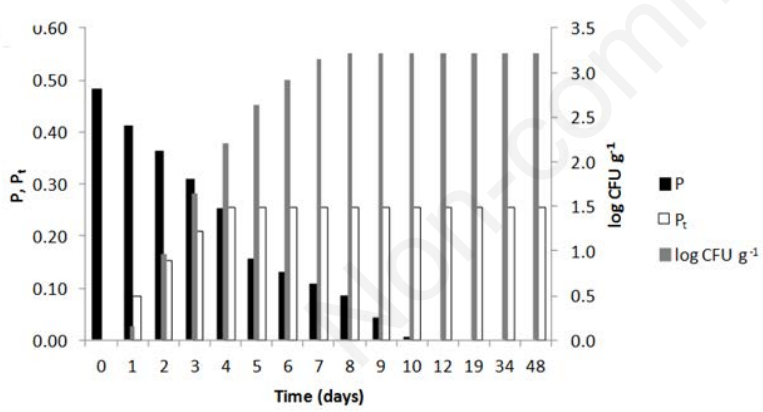

(b)

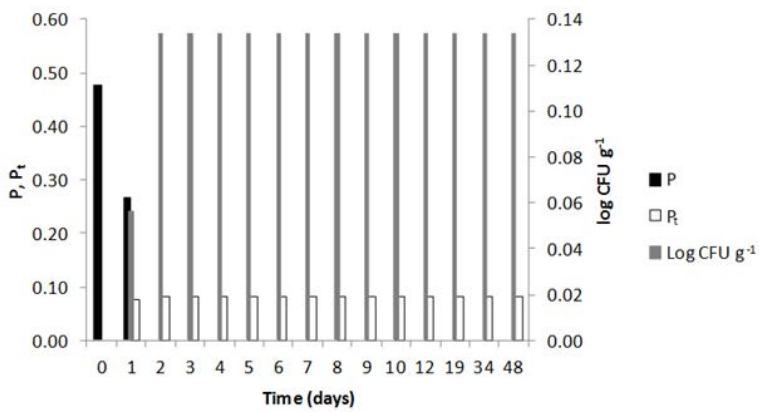

Figure 3. Predicted growth probability (P), time-dependent growth probability $\left(P_{t}\right)$ and growth $\left(\log C F U g^{-1}\right)$ of $L$. monocytogenes in artisanal salami over time in the absence (a) and in the presence (b) of starter cultures.

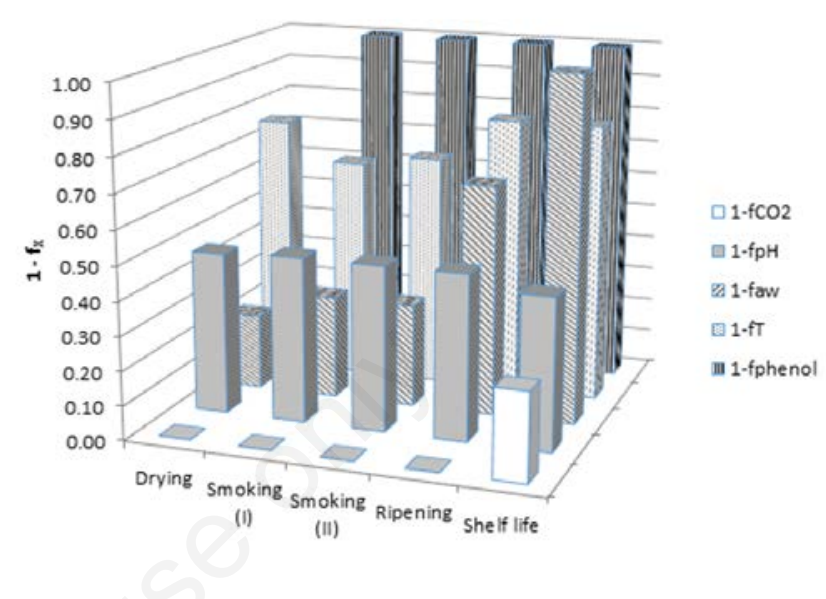

Figure 2. The fractional contribution (expressed as 1-f) of each inhibitory factor to growth probability for $L$. monocytogenes in Pitina.

(a)

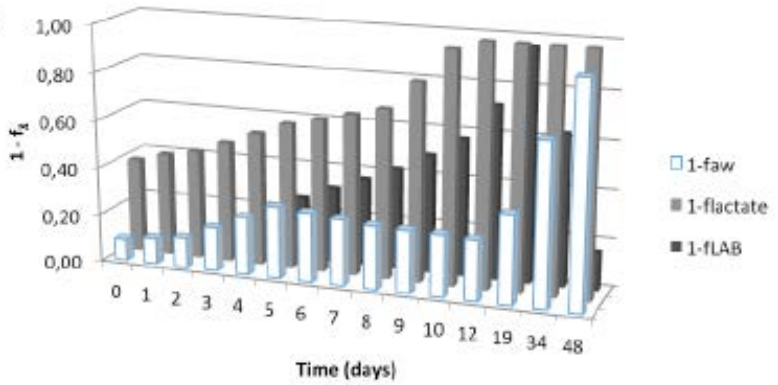

(b)

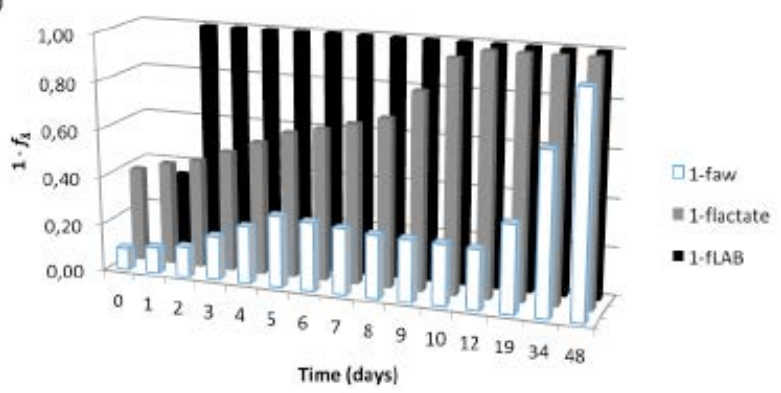

Figure 4. The fractional contribution (expressed as 1-f) of inhibitory factors to growth probability for L. monocytogenes in salami over time in the absence (a) and in the presence (b) of starter cultures. 
preventing the pathogen from exceeding its critical limit. The simultaneous growth of lactic acid bacteria (LAB) and L. monocytogenes was modelled using the Jameson approach (Jameson, 1962), reconsidered by Cornu et al. (2011). Given its prediction capability, PP could be useful in assisting producers of fermented foods, such as salami, in the effective management of preventive and corrective measures.

\section{Conclusions}

The PP application, which incorporates a set of models for various pathogenic bacteria, is intended for practical uses by both specialists and non-specialists. It allows users to evaluate the growth chance, the growth or survival of a pathogen, to quantify the combined effect of various hurdles on the probability of growth even in a time dependent manner, and to define combinations at which growth ceases in a variety of food products. PP may be a valuable tool for producers by assisting them in the safety management of food based on definition of appropriate processing conditions and product formulations for controlling the hazard, and on selecting the maximum safe shelf life based on the likely growth of the pathogen of concern. On the other hand, the tool may be useful for food inspectors in assessing the compliance of food to safety criteria and in assisting auditors when they assess the safety of processes within a food business (validation of procedures - i.e. HACCP - for controlling the hazard).

In conclusion, we hope that this application will represent a bridge between producers and food safety authorities and will assist them in their common commitment towards the production of safer food products.

\section{References}

Baranyi J, Roberts TA, 1995. Mathematics of predictive food microbiology. Int $\mathrm{J}$ Food Microbiol 26:199-218.

Beaufort A, 2011. The determination of ready-to-eat foods into Listeria monocytogenes growth and no growth categories by challenge tests. Food Control 22:1498-502.

Bernaerts K, Dens E, Vereecken K, Geeraerd AH, Standaert AR, Devlieghere F, Debevere J, Van Impe JF, 2004. Concepts and tools for predictive modelling of microbial dynamics. J Food Prot 67:2041-52.

Buchanan RL, Whiting RC, Damert WC,
1997. When is simple good enough: A comparison of the Gompertz, Baranyi, and three-phase linear models for fitting bacterial growth curves. Food Microbiol 14:313-26.

Cornu M, Billoir E, Bergis H, Beaufort A, Zuliani V, 2011. Modeling microbial competition in food: application to the behavior of Listeria monocytogenes and lactic acid flora in pork meat products. Food Microbiol 28:639-47.

European Commission, 2005. Commission Regulation (EC) No. 2073/2005 of 15 November 2005 on microbiological criteria for foodstuffs. In: Official Journal of the European Union, L 338/1, 22/12/2005.

European Commission, 2007. Commission Regulation (EC) No. 1441/2007 of 5 December 2007 amending Regulation (EC) No 2073/2005 on microbiological criteria for foodstuffs. In: Official Journal of the European Union, L 322/1, 07/12/2007.

Jameson JE, 1962. A discussion of the dynamics of Salmonella enrichment. J Hyg 60:193-207.

Mafart P, Couvert O, Gaillard S, Leguerinel I, 2002. On calculating sterility in thermal preservation methods: application of the Weibull frequency distribution model. Int J Food Microbiol 72:107-13.

Koutsoumanis KP, 2001. Predictive modelling of the shelf life of fish under non isothermal conditions. Appl Environ Microbiol 67:1821-9.

McMeekin T, Bowman J, McQuestin O, Mellefont L, Ross T, Tamplin M, 2008. The future of predictive microbiology: strategic research, innovative applications and great expectations. Int J Food Microbiol 128:2-9.

McMeekin TA, Hill C, Wagner M, Dahl A, Ross T, 2010. Ecophysiology of foodborne pathogens: essential knowledge to improve food safety. Int $\mathrm{J}$ Food Microbiol 139:S64-78.

McQuestin OJ, Shadbolt CT, Ross T, 2009. Quantification of the relative effects of temperature, $\mathrm{pH}$, and water activity on inactivation of Escherichia coli in fermented meat by meta-analysis. Appl Environ Microbiol 75:6963-72.

Mejlholm O, Dalgaard P, 2009. Development and validation of an extensive growth and growth boundary model for Listeria monocytogenes in lightly preserved and ready-to-eat shrimp. J Food Prot 72: 2132-43.

Mellefont LA, Ross T, 2003. The effect of abrupt shifts in temperature on the lag phase duration of Escherichia coli and Klebsiella oxytoca. Int $\mathrm{J}$ Food Microbiol 83:295-305.
Polese P, Del Torre M, Spaziani M, Stecchini ML, 2011. A simplified approach for modeling the bacterial growth/no growth boundary. Food Microbiol 28:384-91.

Polese P, Del Torre M, Venir E, Stecchini ML, 2014. A simplified modelling approach established to determine the Listeria monocytogenes behaviour during processing and storage of a traditional (Italian) ready-to-eat food in accordance with the European Commission Regulation 2073/2005. Food Control 36:166-73.

Polese P, Del Torre M, Stecchini ML, 2016. A web-based application customized to food safety requirements of small-sized enterprises. Procedia Food Sci 7:14953.

Polese P, Del Torre M, Stecchini ML, 2017. Prediction of the impact of processing critical conditions for Listeria monocytogenes growth in artisanal dry-fermented sausages (salami) through a growth/no growth model applicable to time-dependent conditions. Food Control 75:167-80.

Pujol L, Kan-King-Yu D, Le Marc Y, Johnston MD, Rama-Heuzard F, Guillou S, McClure P, Membré J-M, 2012. Establishing equivalence for microbial-growth-inhibitory effects ("iso-hurdle rules") by analyzing disparate Listeria monocytogenes data with a gamma-type predictive model. Appl Environ Microbiol 78:1069-80.

Tienungoon S, Ratkowsky DA, McMeekin TA, Ross T, 2000. Growth limits of Listeria monocytogenes as a function of temperature, $\mathrm{pH}, \mathrm{NaCl}$, and lactic acid. Appl Environ Microbiol 66:4979-87.

Zhang D, McQuestin OJ, Mellefont LA, Ross T, 2010. The influence of nonlethal temperature on the rate of inactivation of vegetative bacteria in inimical environments may be independent of bacterial species. Food Microbiol 27:453-9.

Zwietering MH, den Besten HMW, 2011. Modelling: one world for many activities and uses. Food Microbiol 28:81822.

Zwietering MH, Wijtzes T, de Wit JC, van'T Riet K, 1992. A decision support system for prediction of the microbial spoilage in foods. J Food Prot 55:9739. 